in vivo $35: 987-991(2021)$

doi:10.21873/invivo.12341

\title{
Risk Factors for Lymph Node Metastasis in Pathological T1b Colorectal Cancer
}

\author{
ATSUSHI NAITO, KAZUYA IWAMOTO, MASAHISA OHTSUKA, MITSUNOBU IMASATO, \\ YUJIRO NAKAHARA, MANABU MIKAMORI, KENTA FURUKAWA, \\ JEONGHO MOON, TADAFUMI ASAOKA, KENTARO KISHI and HIROKI AKAMATSU \\ Department of Surgery, Osaka Police Hospital, Osaka, Japan
}

\begin{abstract}
Background/Aim: The rate of lymph node metastasis (LNM) of colorectal carcinoma (CRC) with a submucosal (SM) invasion depth of $1000 \mu \mathrm{m}$ or more can reach $12.5 \%$, which is the most common reason for additional resection in daily practice. Other studies have reported that the rate of LNM is less than $2 \%$, regardless of the depth of invasion, if the lesions show good histology, lymphovascular infiltration is negative, and tumor budding is limited. The purpose of this study was to investigate new risk factors for LNM in T1b colorectal cancer. Patients and Methods: The 239 patients who were diagnosed with pathological T1b CRC after colorectal surgical resection at the Osaka Police Hospital in Japan between January 2008 and December 2018 were retrospectively reviewed in this study. Results: The LNM rate was $11.3 \%$ (27/239). The variables identified as being significant factors using multivariate analysis were: i) lymphatic invasion (Ly)-positive [odds ratio $(O R)=5.97 ; 95 \%$ confidence interval $(C I)=2.27-15.74]$, ii) female gender $(O R=3.49 ; 95 \% C I=1.38-8.85)$, and iii) left-sided colorectal involvement ( $O R=4.98 ; 95 \% C I=1.22-20.39)$. If none of these risk factors were present with $T 1 b$, the LNM rate was 0\% (0/28). Conclusions: Ly-positive, female gender, and leftsided colorectal involvement could be risk factors for LNM in $T 1 b C R C$.
\end{abstract}

Colorectal cancer (CRC) is the third most common cancer in the world (1). With the increase in the implementation of CRC screening programs, the frequency of early cancer is expected to increase. (2). The recently reported favorable

This article is freely accessible online.

Correspondence to: Atsushi Naito, Department of Surgery, Osaka Police Hospital, 10-31 Kitayama-cho, Tennouji-ku, Osaka City, Osaka 543-0035, Japan. Tel: +81 667716051, Fax: +81 667752838, e-mail: naito.atsu@gmail.com

Key Words: Lymph node metastasis, risk factor, T1b colorectal cancer. long-term results of endoscopic resection (ER) for T1 CRC suggest that superficial T1 CRC with a submucosal (SM) invasion depth of less than $1000 \mu \mathrm{m}$ may have a very low risk of metastasis $(3,4)$. ER is considered an attractive therapeutic option for T1 CRC because of its less invasive profile compared to surgical resection (5). Surgical resection is recommended when the vertical margin is positive. However, if the vertical margin is negative, surgical resection is recommended in cases of: i) T1b (depth of SM invasion $\geq 1000 \mu \mathrm{m}$ ), ii) lymphovascular invasion-positive, iii) undifferentiated histopathological types (poorly differentiated adenocarcinoma, signet-ring cell carcinoma, or mucinous carcinoma), or iv) budding grade of BD2/3 (6). According to the results of a study by the Japanese Society for Cancer of the Colon and Rectum (JSCCR), the lymph node metastasis (LNM) rate of CRC with an SM invasion depth of $1000 \mu \mathrm{m}$ or more was $12.5 \%$ (7). On the other hand, several studies have reported that the rate of LNM was less than $2 \%$, regardless of the depth of invasion, if the lesions showed good histology, no lymphovascular infiltration, and limited tumor budding $(8,9)$. In a study of 548 cases of T1 cancer, deep invasion was found in $89.8 \%$ of the additional resections (10), which is the most common reason for additional resection in daily practice.

The purpose of this study was to investigate new risk factors for LNM in T1b CRC.

\section{Patients and Methods}

Patient selection, data extraction, and definitions. Patients diagnosed with pathological T1b CRC after colorectal surgical resection at the Osaka Police Hospital in Japan between January 2008 and December 2018 were included in this study. The exclusion criteria were i) synchronous CRC, ii) concomitant surgical procedures for other cancers, iii) local recurrence after ER, iv) distant metastasis, or v) treatment other than surgery.

Information on various clinicopathological factors of the patients, including sex, age, tumor location, histological type, and LNM, was obtained from medical records and retrospectively analyzed. Histological types were classified as either differentiated 
(differentiated papillary, well or moderately differentiated tubular adenocarcinoma) or undifferentiated (undifferentiated and poorly differentiated adenocarcinoma, signet-ring cell carcinoma, or mucinous carcinoma). Tumor budding was not included due to low reporting rate in the pathology reports.

Tumors arising from the cecum to the ascending and transverse colon were defined as tumors on the right side, and tumors arising from the descending colon to the rectum were defined as tumors on the left side.

This study was reviewed and approved by the institutional review boards of the participating institutions. Written consent was obtained from each patients.

Statistical analysis. Clinicopathological factors were analyzed using Pearson's Chi-squared test and Fisher's exact test. Variables found to be significant in univariate analysis were analyzed by multivariate logistic regression analysis. If the $95 \%$ confidence interval (CI) for the odds ratio (OR) did not include 1.0 , and if $p$-value $<0.05$, the difference was considered significant. All statistical analyses were performed using JMP version 14.0 (SAS Institute, Cary, NC).

\section{Results}

The baseline characteristics of all patients $(n=239)$ are presented in Table I. A total of 142 patients (59.4\%) were treated with colorectal surgical resection alone as an initial treatment (surgery alone), and 97 patients (40.6\%) underwent additional colorectal surgical resection after initial ER (surgery after ER). The number of patients positive for LNM was $27(11.3 \%)$.

Risk factors for LNM in T1b CRC. Univariate analysis showed a significant difference in four risk factors (Table II), and the factors that were significantly different on multivariate analysis were: i) lymphatic invasion (Ly)positive $(\mathrm{OR}=5.97 ; 95 \% \mathrm{CI}=2.27-15.74)$, ii $)$ female gender $(\mathrm{OR}=3.49$; 95\% CI=1.38-8.85), and iii) left-sided colorectal involvement $(\mathrm{OR}=4.98 ; 95 \% \mathrm{CI}=1.22-20.39)$. Of these variables, Ly-positive had the highest OR (Table III).

The LNM rates for each combination of risk factors in this study (Ly-positive, female gender, left-sided colorectal involvement) are shown in Table IV. If no risk factors were present with $\mathrm{T} 1 \mathrm{~b}$ (depth of $\mathrm{SM}$ invasion $\geq 1,000 \mu \mathrm{m}$ ), the rate of LNM was $0 \%$; if one risk factor was present, the rate was $2.7 \%$; if two risk factors were present, the rate was $22.8 \%$; and if all three risk factors were present, the rate was $31.6 \%$. Thus, the rate of LNM increased with the number of positive risk factors, and when only $\mathrm{T} 1 \mathrm{~b}$ without the three risk factors was present, it was $0 \%$.

\section{Discussion}

It has been reported that the rate of LNM is $0 \%$ if the depth of invasion is $<1,000 \mu \mathrm{m}$ (7). In routine practice, T1b is the most commonly encountered reason for additional resection of T1 CRC (10). Colorectal surgery is still associated with
Table I. Baseline characteristics.

\begin{tabular}{|c|c|}
\hline Number of cases & 239 \\
\hline Age, years, median (range) & $67(27-87)$ \\
\hline \multicolumn{2}{|l|}{ Gender } \\
\hline Male, n (\%) & $152(63.6)$ \\
\hline Female, n (\%) & $87(36.4)$ \\
\hline \multicolumn{2}{|l|}{ Tumor location } \\
\hline Right-sided colorectum, n (\%) & $171(71.5)$ \\
\hline Left-sided colorectum, n (\%) & $68(28.5)$ \\
\hline \multicolumn{2}{|l|}{ Procedure } \\
\hline Laparoscopic surgery, n (\%) & $230(96.2)$ \\
\hline Open surgery, n (\%) & $9(3.8)$ \\
\hline \multicolumn{2}{|l|}{ Lymph node dissection } \\
\hline $\mathrm{D} 2, \mathrm{n}(\%)$ & $175(73.2)$ \\
\hline D3, n (\%) & $64(26.8)$ \\
\hline \multicolumn{2}{|l|}{ Initial treatment } \\
\hline Surgery alone, n (\%) & $142(59.4)$ \\
\hline Surgery after ER, n (\%) & $97(40.6)$ \\
\hline \multicolumn{2}{|l|}{ Lymphatic invasion } \\
\hline Positive, n (\%) & $70(29.3 \%)$ \\
\hline Negative, n (\%) & $169(70.7 \%)$ \\
\hline \multicolumn{2}{|l|}{ Venous invasion } \\
\hline Positive, n (\%) & $62(25.9 \%)$ \\
\hline Negative, n (\%) & $177(74.1 \%)$ \\
\hline \multicolumn{2}{|l|}{ Histological type } \\
\hline Dif, n (\%) & $235(98.3 \%)$ \\
\hline Undif, n (\%) & $4(1.7 \%)$ \\
\hline \multicolumn{2}{|l|}{ Lymph node metastasis } \\
\hline Positive, n (\%) & $27(11.3 \%)$ \\
\hline Negative, n (\%) & $212(88.7 \%)$ \\
\hline
\end{tabular}

ER: Endoscopic resection; Dif: papillary, well or moderately differentiated tubular adenocarcinoma; Undif: poorly differentiated adenocarcinoma, signet-ring cell carcinoma, or mucinous carcinoma.

considerable morbidity and mortality $(11,12)$. Identification of factors that determine the indication for surgery is desperately needed. In the present study, three risk factors: i) Ly-positive, ii) female gender, and iii) left-sided colorectal involvement, were identified for LNM. In our study, when $\mathrm{T} 1 \mathrm{~b}$ was the only pathological risk factor in T1 CRC, the rate of LNM was extremely low, at $4.3 \%$. In the absence of the three factors identified in the present study, the LNM rate was even less, at $0 \%$. The three risk factors that were identified seemed to correlate better with LNM than those reported in the JSCCR guidelines (6).

Ly-positive had the highest odds ratio. The relationship between this factor and LNM has been widely reported and appears to be reliable (13). There was no significant variation in the extend of venous invasion with respect to histological type in the present study. This may be due to the small sample size. Tumor budding was not included, due to their low rates found in the pathology reports.

Second, female patients were at a higher risk of LNM compared to male patients. This has been shown in another large study (14). However, there were no significant 
Table II. Univariate analysis of the risk factors for lymph node metastasis.

\begin{tabular}{|c|c|c|c|c|}
\hline & $\begin{array}{c}\operatorname{LNM}(+) \\
(\mathrm{n}=27)\end{array}$ & $\begin{array}{c}\mathrm{LNM}(-) \\
(\mathrm{n}=212)\end{array}$ & OR $(95 \% \mathrm{CI})$ & $p$-Value \\
\hline \multicolumn{5}{|l|}{ Age, years } \\
\hline$<65$, n $(\%)$ & $12(13.6 \%)$ & $76(35.8)$ & $1.43(0.64-3.22)$ & 0.3881 \\
\hline$\geq 65, \mathrm{n}(\%)$ & $15(9.9 \%)$ & $136(64.2)$ & & \\
\hline \multicolumn{5}{|l|}{ Gender } \\
\hline Female, n (\%) & $15(17.2 \%)$ & $72(34.0)$ & $2.43(1.08-5.47)$ & 0.0314 \\
\hline Male, n (\%) & $12(7.9 \%)$ & $140(66.0)$ & & \\
\hline \multicolumn{5}{|l|}{ Tumor location } \\
\hline Left-sided colorectum, n (\%) & $24(14.0 \%)$ & $147(69.3)$ & $3.54(1.03-12.17)$ & 0.0216 \\
\hline Right-sided colorectum, n (\%) & $3(4.4 \%)$ & $65(30.7)$ & & \\
\hline \multicolumn{5}{|l|}{ Initial treatment } \\
\hline Surgery after ER, n (\%) & $10(10.3 \%)$ & $87(41.0)$ & $0.85(0.37-1.93)$ & 0.6888 \\
\hline Surgery alone, n (\%) & $27(11.3 \%)$ & $125(59.0)$ & & \\
\hline \multicolumn{5}{|l|}{ Lymphatic invasion } \\
\hline Positive, n (\%) & $18(25.7 \%)$ & $52(24.5)$ & $6.15(2.61-14.53)$ & $<0.0001$ \\
\hline Negative, n (\%) & $9(5.3 \%)$ & $160(75.5)$ & & \\
\hline \multicolumn{5}{|l|}{ Venous invasion } \\
\hline Positive, n (\%) & $13(21.0 \%)$ & $49(23.1)$ & $3.09(1.36-7.01)$ & 0.0081 \\
\hline Negative, n (\%) & $14(7.9 \%)$ & $163(76.9)$ & & \\
\hline \multicolumn{5}{|l|}{ Histological type } \\
\hline Undif, n (\%) & $1(25.0 \%)$ & $3(1.4 \%)$ & $2.68(0.27-26.71)$ & 0.4406 \\
\hline Dif, $\mathrm{n}(\%)$ & $26(11.0 \%)$ & $209(98.6 \%)$ & & \\
\hline
\end{tabular}

Dif: Papillary, well or moderately differentiated tubular adenocarcinoma; Undif: poorly differentiated adenocarcinoma, signet-ring cell carcinoma, or mucinous carcinoma; CI: confidence interval; OR: odds ratio; ER: endoscopic resection.

differences between males and females with location, age, morphology, or pathological factors in that paper. There have been several other reports on the association between patient sex and $\operatorname{LNM}(7,15,16)$, however, no significant relationship between patient sex and LNM risk in patients with $\mathrm{T} 1$ cancer was demonstrated, and further studies are required to clarify the lack or verification of this association.

Furthermore, left-sided colorectal tumor was a risk factor. Although the relationship between LNM and left-right body axis differences has not been reported, a high incidence of LNM has been reported in the rectum (17). The rectum has a well-developed anatomical collateral circulation, which may increase the likelihood of an invading tumor encountering a vessel. The left-sided colorectum contains the rectum, which may explain the difference in LNM.

This study has certain limitations, such as the small number of patients, and the fact that it was a retrospective, single-institute study. Thus, further large and multiinstitutional studies are needed to confirm our findings.

In conclusion, we found that when $\mathrm{T} 1 \mathrm{~b}$ is the only pathological risk factor in T1 CRC, the rate of LNM is exceedingly low, however, Ly-positive, female, and leftsided colorectal involvement are potential risk factors for LNM.
Table III. Multivariate analysis of the risk factors for lymph node metastasis.

\begin{tabular}{llll}
\hline & OR & \multicolumn{1}{c}{$95 \%$ CI } & $p$-Value \\
\hline Lymphatic invasion-positive & 5.97 & $2.27-15.74$ & 0.0003 \\
Female & 3.49 & $1.38-8.85$ & 0.0085 \\
Left-sided colorectal & 4.98 & $1.22-20.39$ & 0.0255 \\
\hline
\end{tabular}

CI: Confidence interval; OR: odds ratio.

\section{Conflicts of Interest}

The Authors declare no conflicts of interest associated with this manuscript.

\section{Authors' Contributions}

Study concept and design, data analysis and interpretation, statistical analysis and manuscript preparation were done by AN. Data acquisition was done by MO, quality control of data and algorithms were done by MI and AN. Manuscript editing was done by HA and manuscript review by KI, YN, MM, KF, JM, $\mathrm{TA}$, and $\mathrm{KK}$. 
Table IV. Relationship between the number of risk factors in the present study and lymph node metastasis.

\begin{tabular}{|c|c|c|c|c|}
\hline Risk factors & $\operatorname{LNM}(+)$ & LNM (-) & Total & Incidence of LNM (\%) \\
\hline No risk factors & 0 & 28 & 28 & 0 \\
\hline One risk factor & 3 & 110 & 113 & 2.7 \\
\hline a. Lymphatic invasion-positive & 0 & 8 & 8 & 0 \\
\hline b. Female & 0 & 25 & 25 & 0 \\
\hline c. Left-sided colorectal & 3 & 77 & 80 & 3.8 \\
\hline Two risk factors & 18 & 61 & 79 & 22.8 \\
\hline$a+b$ & 3 & 4 & 7 & 42.6 \\
\hline$a+c$ & 9 & 27 & 36 & 25.0 \\
\hline$b+c$ & 6 & 30 & 36 & 16.7 \\
\hline Three risk factors & 6 & 13 & 19 & 31.6 \\
\hline
\end{tabular}

LNM: Lymph node metastasis.

\section{Acknowledgements}

The Authors are grateful for the efforts of our past and present members of the hospital.

\section{References}

1 Bray F, Ferlay J, Soerjomataram I, Siegel RL, Torre LA and Jemal A: Global cancer statistics 2018: GLOBOCAN estimates of incidence and mortality worldwide for 36 cancers in 185 countries. CA Cancer J Clin 68(6): 394-424, 2018. PMID: 30207593. DOI: $10.3322 /$ caac. 21492

2 Gupta AK, Melton LJ, Petersen GM, Timmons LJ, Vege SS, Harmsen WS, Diehl NN, Zinsmeister AR and Ahlquist DA: Changing trends in the incidence, stage, survival, and screendetection of colorectal cancer: A population-based study. Clin Gastroenterol Hepatol 3(2): 150-158, 2005. PMID: 15704049. DOI: $10.1016 / \mathrm{s} 1542-3565(04) 00664-0$

3 Choi JY, Jung SA, Shim KN, Cho WY, Keum B, Byeon JS, Huh KC, Jang BI, Chang DK, Jung HY and Kong KA: Meta-analysis of predictive clinicopathologic factors for lymph node metastasis in patients with early colorectal carcinoma. J Korean Med Sci 30(4): 398-406, 2015. PMID: 25829807. DOI: 10.3346/ jkms.2015.30.4.398

4 Wada H, Shiozawa M, Katayama K, Okamoto N, Miyagi Y, Rino Y, Masuda M and Akaike M: Systematic review and metaanalysis of histopathological predictive factors for lymph node metastasis in T1 colorectal cancer. J Gastroenterol 50(7): 727734, 2015. PMID: 25725617. DOI: 10.1007/s00535-015-1057-0

5 Sako T, Kudo S-E, Miyachi H, Wakamura K, Igarashi K, Misawa M, Mori Y, Kudo T, Hayashi T, Katagiri A, Ishida F, Azuma $\mathrm{T}$, Inoue $\mathrm{H}$ and Hamatani $\mathrm{S}$ : A novel ability of endocytoscopy to diagnose histological grade of differentiation in T1 colorectal carcinomas. Endoscopy 50(1): 69-74, 2018. PMID: 28962043. DOI: 10.1055/s-0043-117403

6 Hashiguchi Y, Muro K, Saito Y, Ito Y, Ajioka Y, Hamaguchi T, Hasegawa $K$, Hotta $K$, Ishida $H$, Ishiguro $M$, Ishihara $S$, Kanemitsu Y, Kinugasa Y, Murofushi K, Nakajima TE, Oka S, Tanaka T, Taniguchi H, Tsuji A, Uehara K, Ueno H, Yamanaka T, Yamazaki K, Yoshida M, Yoshino T, Itabashi M, Sakamaki K, Sano K, Shimada Y, Tanaka S, Uetake H, Yamaguchi S,
Yamaguchi N, Kobayashi H, Matsuda K, Kotake K and Sugihara $\mathrm{K}$ : Japanese Society for Cancer of the Colon and Rectum (JSCCR) guidelines 2019 for the treatment of colorectal cancer. Int J Clin Oncol 25(1): 1-42, 2020. PMID: 31203527. DOI: 10.1007/s10147-019-01485-z

7 Kitajima K, Fujimori T, Fuji S, Takeda J, Ohkura Y, Kawamata H, Kumamoto T, Ishiguro S, Kato Y, Shimoda T, Iwashita A, Ajioka Y, Watanabe H, Watanabe T, Muto T and Nagasako K: Correlations between lymph node metastasis and depth of submucosal invasion in submucosal invasive colorectal carcinoma: A Japanese collaborative study. J Gastroenterol 39(6): 534-543, 2004. PMID: 15235870. DOI: 10.1007/s00535004-1339-4

8 Nakadoi K, Tanaka S, Kanao H, Terasaki M, Takata S, Oka S, Yoshida S, Arihiro K and Chayama K: Management of T1 colorectal carcinoma with special reference to criteria for curative endoscopic resection. J Gastroenterol Hepatol 27(6): 1057-1062, 2012. PMID: 22142484. DOI: 10.1111/j.14401746.2011.07041.x

9 Kobayashi H, Higuchi T, Uetake H, Iida S, Ishikawa T, Ishiguro $\mathrm{M}$ and Sugihara K: Resection with en bloc removal of regional lymph node after endoscopic resection for T1 colorectal cancer. Ann Surg Oncol 19(13): 4161-4167, 2012. PMID: 22772868. DOI: $10.1245 / \mathrm{s} 10434-012-2471-7$

10 Yamaoka Y, Imai K, Shiomi A, Kagawa H, Hino H, Yamakawa Y, Yamaguchi T, Kinugasa Y, Kishida Y, Ito S, Hotta K and Imai $\mathrm{T}$ : Endoscopic resection of T1 colorectal cancer prior to surgery does not affect surgical adverse events and recurrence. Surg Endosc 34(11): 5006-5016, 2019. PMID: 31820150. DOI: 10.1007/s00464-019-07295-8

11 Panis Y, Maggiori L, Caranhac G, Bretagnol F and Vicaut E: Mortality after colorectal cancer surgery: A french survey of more than 84,000 patients. Ann Surg 254(5): 738-743, 2011. PMID: 21997816. DOI: 10.1097/SLA.0b013e31823604ac

12 Wexner SD: Postoperative mortality and morbidity in French patients undergoing colorectal surgery - invited critique. Arch Surg 140(3): 284, 2005. PMID: 15781793. DOI: 10.1001/ archsurg.140.3.278

13 Watanabe T, Muro K, Ajioka Y, Hashiguchi Y, Ito Y, Saito Y, Hamaguchi T, Ishida H, Ishiguro M, Ishihara S, Kanemitsu Y, Kawano H, Kinugasa Y, Kokudo N, Murofushi K, Nakajima T, Oka S, Sakai Y, Tsuji A, Uehara K, Ueno H, Yamazaki K, 
Yoshida M, Yoshino T, Boku N, Fujimori T, Itabashi M, Koinuma N, Morita T, Nishimura G, Sakata Y, Shimada Y, Takahashi K, Tanaka S, Tsuruta O, Yamaguchi T, Yamaguchi N, Tanaka T, Kotake K and Sugihara K: Japanese Society for Cancer of the Colon and Rectum (JSCCR) guidelines 2016 for the treatment of colorectal cancer. Int J Clin Oncol 23(1): 1-34, 2018. PMID: 28349281. DOI: 10.1007/s10147-017-1101-6

14 Miyachi H, Kudo SE, Ichimasa K, Hisayuki T, Oikawa H, Matsudaira S, Kouyama Y, Kimura YJ, Misawa M, Mori Y, Ogata N, Kudo T, Kodama K, Hayashi T, Wakamura K, Katagiri A, Baba T, Hidaka E, Ishida F, Kohashi K and Hamatani S: Management of T1 colorectal cancers after endoscopic treatment based on the risk stratification of lymph node metastasis. J Gastroenterol Hepatol 31(6): 1126-1132, 2016. PMID: 26641025. DOI: 10.1111 jgh.13257

15 Nakadoi K, Oka S, Tanaka S, Hayashi N, Terasaki M, Arihiro $\mathrm{K}$, Shimamoto $\mathrm{F}$ and Chayama K: Condition of muscularis mucosae is a risk factor for lymph node metastasis in $\mathrm{T} 1$ colorectal carcinoma. Surg Endosc 28(4): 1269-1276, 2014. PMID: 24281433. DOI: 10.1007/s00464-013-3321-9
16 Samuolis N, Samalavicius NE, Dulskas A, Markelis R, Lunevicius R, Mickys U and Ringeleviciute U: Surgical or endoscopic management of malignant colon polyps. ANZ J Surg 88(12): E824-E828, 2018. PMID: 30347496. DOI: 10.1111/ ans.14846

17 Yasue C, Chino A, Takamatsu M, Namikawa K, Ide D, Saito S, Igarashi $\mathrm{M}$ and Fujisaki J: Pathological risk factors and predictive endoscopic factors for lymph node metastasis of $\mathrm{T} 1$ colorectal cancer: a single-center study of 846 lesions. J Gastroenterol 54(8): 708-717, 2019. PMID: 30810812. DOI: $10.1007 / \mathrm{s} 00535-019-01564-\mathrm{y}$
Received October 26, 2020

Revised December 4, 2020

Accepted December 10, 2020 